\title{
Cost-Effective Different Ladies Jewelry from Leather Products Wastages
}

\author{
Md. Abdulla-Al-Mamun \\ Assisstant Professor, \\ Institute of Leather Engineering and Technology, \\ University of Dhaka, 44-50 Hazaribagh, Dhaka-1209, \\ Bangladesh \\ Adhir Chandra Paul \\ Assistant Professor, \\ Department of Leather Engineering, \\ Khulna University of Engineering \&Technology, \\ Khulna-9203, Bangladesh
}

\author{
Rajan Kumar Raha \\ Assistant Professor, \\ Department of Leather Engineering, \\ Khulna University of Engineering \&Technology, \\ Khulna-9203, Bangladesh \\ Tasmin Wazeda Binty \\ Student (BE) \\ Institute of Leather Engineering and Technology, \\ University of Dhaka, 44-50 Hazaribagh, Dhaka-1209, \\ Bangladesh
}

\begin{abstract}
Large amounts of leather-cutting wastages have been generated for the production of leather-goods in the industry. Nowadays, the solid waste management is difficult challenge and important concern for sustainable and cleaner processing to minimize the wastage by recycling/re-use. Our present study is about the development to make the different types of ladies-jewelry such as Bracelet/Anklet, Necklace, Earrings, Ring, and Bangles from the leather cutting wastages. The patterns making and cost calculation was evaluated by the systemic way. Finally, the jewelry was survey through to the $\mathbf{5 0}$ female student (age range: 18 30 years) by a questionnaire. The questionnaire involves five different sector, they are wearing comfort, fashion fact, quality, costing $\&$ interest in buying and recommendations. The items are rated on a scale of 1 to 5 , where 1 being "strongly disagree", 2 being "disagree", 3 being "average/ undecided", 4 being "agree" and 5 being "strongly agree". The statistical analysis such as level of satisfaction, median, coefficient of variance $(\mathrm{CV})$, variance, Standard Deviation (STDEV) and mean value were calculated by a systemic way. The survey results shows the Level of satisfaction value greater than $70 \%$ of each cases and it's a satisfactory level.
\end{abstract}

Keywords:- Leather product; Wastage; Recycle; Re-use; Costeffectiveness, Fashionable item

\section{INTRODUCTION}

Leather has played an important role in day-to-day life of humankind from immemorial. Human from the very beginning, has been using animal skins for covering their body \& legs from climate conditions, keeping the provisions of water in goatskins and making the belts for various purposes. From ancient civilization to modern times, the human race one from has used leather or the other in its daily life and it is discovered everywhere. It's seems the humankind can hardly do without these useful materials.

The global need for leather products is steadily flourishing an aptitude like to walk because of population swelling and economic improvement [1]. Sustain raise competitiveness of an economy is an impress of economic power and permanence of that economy [2]. The term 'Leather Goods' is applied \& confined generally to the articles or goods made, mainly of leather \& intended for carrying personal belongings, such as the smaller items, which can be carried in hand or shoulder. The variety of leather goods we come across everyday is countless. When there are a variety of articles that differs so much in size, design \& method of construction, then it is necessary to classify them into separate convenient articles of similar kind. In this report, classification of leather good has been defined in confined terms [3].

The undesired portion of the any material, especially for leather, lining materials, reinforcement materials etc, that are left after cutting the material is called wastage/waste materials.

The cuttability grades of leather; on first grade leather, normally an allowance of 3\% is given while on the other grade it is varied by 5\% [4]. Since only about $50-55 \%$ of corium collagen actually ends up as finished leather it is not surprising that a tannery generates large amounts of solid wastes. As a matter of fact, utilization and/or disposal of solid waste is one of the most difficult challenges especially in countries with confined legislation and enforcement pertaining to waste handling. Moreover, it is very likely that the pressures will escalate further. $1000 \mathrm{~kg}$ of wet salted cattle hides, weight class about $25.6 \mathrm{~kg}$ per hide processed to shoe uppers, about $5 \sim 10 \mathrm{~kg}$ finished leather trimmings have been produced [5].

Design \& development (pattern development is the offshoot of design \& development) is of utmost importance for processing and marketing of leather goods. Without proper conception or grasp of functional value, no design could convert into a fabricated product and such work relating to the design and pattern development aspect of leather goods manufacturing cannot be over-emphasized.

For performing the above task, a leather-cutting wastagesproduct must have a unique-design and a broad outline of what have originated before the advent of design in dealt with, it started first with the purpose of utility. This paper, tries to make a market-demand products and survey the product through to the 50 female students. In addition, it can enhance the quality \& effectiveness of cost of leather-jewelry that could be mostly demanded for the women and maximum 
utilization of value-added product to decreases the solid waste of a leather-goods industry.

\section{MATERIALS AND METHOD}

A. Selecting leather-wastages for the manufacturing of jewellary

The wastages trimming was collected from a leather industry as shown in Fig. 1 and sort out the cutting based on cow, goat, sheep or calfskins. An extensive range of color and design widen the selection range, which encourage the prospective consumers to put these products to use in a multitude of ways, be it fashionable or functional. Based on this task, the wastage was another sorting based on color and jewelry fashion fact.

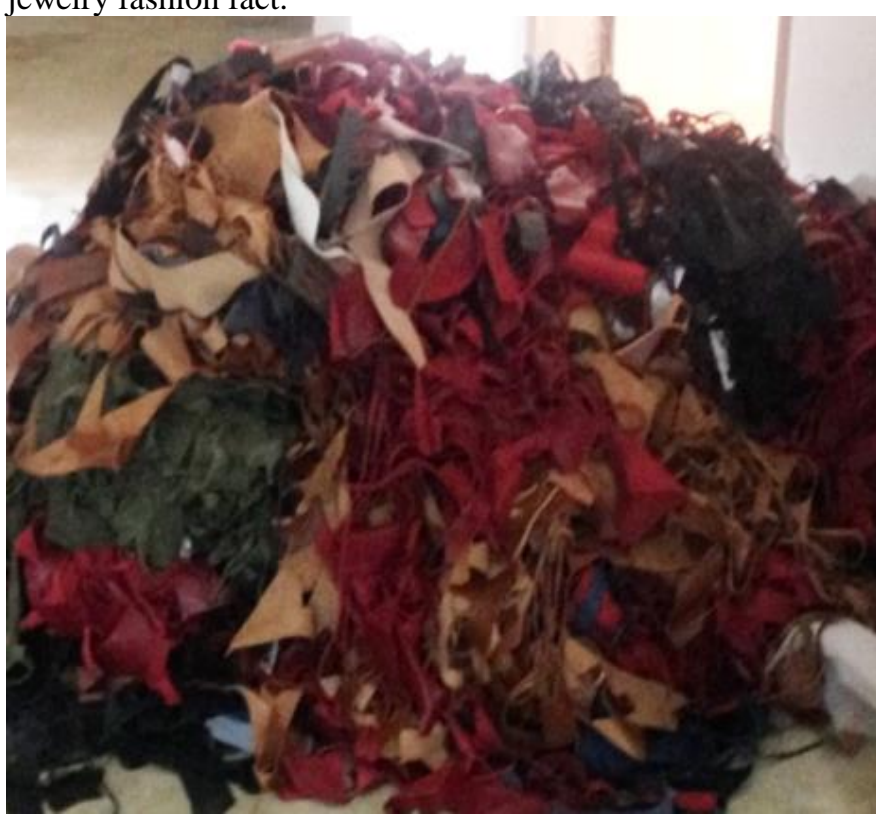

Fig. 1. Collection of leather wastages

B. Sequential Operation of Different Parts of Bracelet

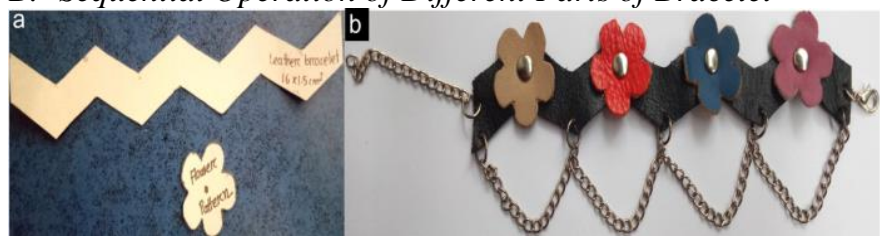

Fig. 2. Preparation of leather bracelet, (a) Patterns (b) Final view of bracelet

The patterns and final view of bracelet is shown in Fig. 2. Materials were used the wastage leather, metal chain, rivet and metal ring. The tools and equipment was used Pattern paper, Measuring tape, Anti-cutter, Puncher, Hammer, and Pliers. Leather consumption was approximately 0.0575 sq. $\mathrm{ft}$ per bracelet. The making procedure was as follows: At first we visualized and prepared a design of a bracelet. Then we prepare the master pattern. According to our design, at first the flowers were made followed by marking the position of flower attachment were done. After that the base pattern was cut within the flowers and splitting \& skiving were done for thickness adjustment. Finally, assembling and finishing were done to ensure the quality. The net costing of final bracletjewelry was approximately 39 BDT whereas the market price of the same item is about 100 350 taka.

\section{Sequential Operation of Different Parts of Necklace}

At first, we visualized and prepared a design of Necklace. Then we prepare the master pattern. According to our design, first we have to make the leather flowers. Then we prepared the others component. Master pattern of different parts of the necklace is shows in Fig. 3 (a) and final product shown in Fig. 3 (b). The operational procedure of necklace started with the pattern and finished by the assembling the leather and other accessories.

Materials have been used wastage-leather, adhesive, stone, beads, metal chain and lock, and thread. The tools and equipment was used same as bracelet except marking pen. Leather consumption was approximately 0.54 sq. ft. for a single necklace. All the components were cut based on master pattern.
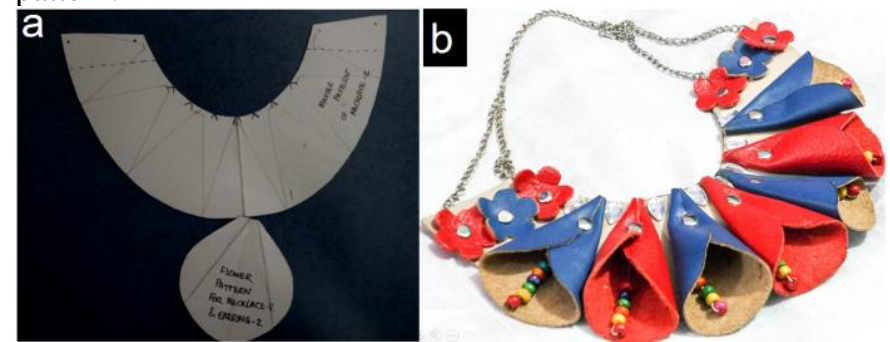

Fig. 3. Preparation of leather necklace, (a) Patterns (b) Final view of necklace.

Then assembling the parts were done as follows: At first the master pattern was placed on the leather and the flowers were made $\rightarrow$ Beads with threads were added inside the flowers $\rightarrow$ Attachment of the flowers on the base leather was done by using adhesive $\rightarrow$ Rivet was added to attach the flower $\rightarrow$ Then side flowers were added with rivet $\rightarrow$ Stone was assembled to the base leather $\rightarrow$ Joining of metal chain and lock was done. Finally, After assembling we have to look the outer portion of the Necklace. Then we have to control the quality. We have to cut the extra thread and remove the excess adhesives on the surface of leather and burning the edge of the thread. We tried our best to make the necklace decorative and attractive, which will fulfill the customer requirements. The costing of final necklace-jewelry ca. 107 BD taka and market same item price about 350 1000 taka.

\section{Sequential Operation of Different Parts of Earring}

Master pattern of the earring is shows in Fig. 4 (a) and final product shows in Fig. 4 (b). The preoperational procedure of necklace by the pattern and then assembling the leather and other accessories.
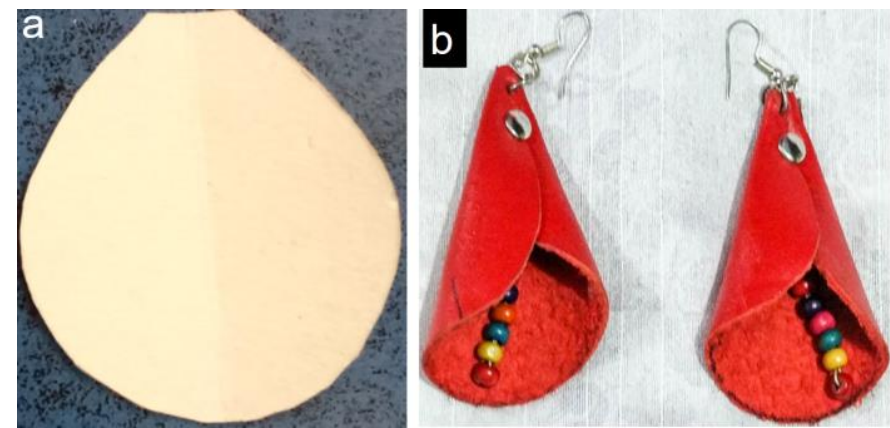

Fig. 4. Preparation of leather-earrings, (a) Patterns (b) Final view of earrings. 
Materials have been used wastage-leather, metal hook, rivet, beads and thread. The tools and equipment was used same as bracelet. Leather consumption is approximately 0.088 sq. ft. cut the all component based on master pattern. The way we have done the whole procedure can be classified into the following categories: i. Designing \& pattern making, ii. Cutting, iii. Assembling, and iv. Finishing. After, final assembling we have to look the outer portion of the earring. Then we have to control the quality. We tried our best to make the erring decorative and attractive, which will fulfill the customer requirements. The costing of final erring-jewelry ca. 32 BD taka and market same item price about 150 300 taka.

\section{E. Sequential Operation of Different Parts of Ring}

Master pattern of the ring is shows in Fig. 5 (a) and final product shows in Fig. 5 (b). The preoperational procedure of ring by the pattern and then assembling the leather and other accessories.
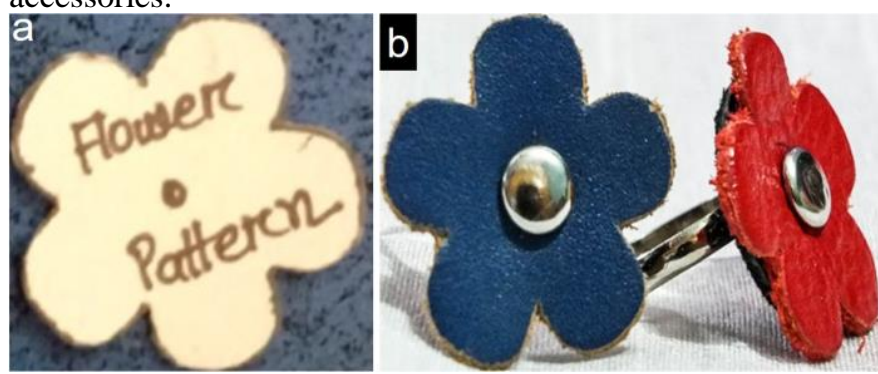

Fig. 5. Preparation of leather-ring, (a) Patterns (b) Final view of ring.

Materials have been used wastage-leather, metal ring and rivet. The tools and equipment was used Pattern paper, Hot glue gun, Anti-cutter, Puncher, Hammer, and Pliers. Leather consumption is approximately 0.01575 sq. ft. cut the all component based on master pattern. The way we have done the whole procedure categories into the following categories: i. Designing \& pattern making, ii. Cutting, iii. Assembling, and iv. Finishing. After, final assembling we have to look the outer portion of ring. Then we have to control the quality. We tried our best to make the erring decorative and attractive, which will fulfill the customer requirements. The costing of final ring ca. $12 \mathrm{BD}$ taka and market same item price about 60 150 taka.

\section{F. Sequential Operation of Different Parts of Bangle}
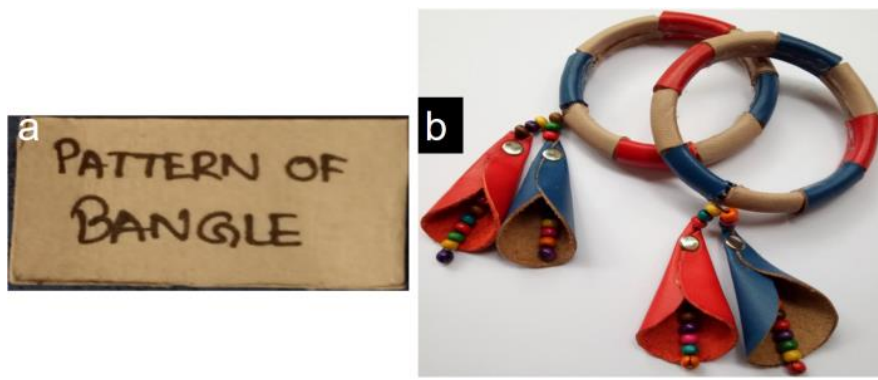

Fig. 6. Preparation of leather-bangle, (a) Basic Patterns (b) Final view of bangle.

The patterns and final view of bangle is shows in Fig. 6 . Materials was used the wastage leather, and wooden frame. The tools and equipment was used Pattern paper, Measuring tape, Anti-cutter, Thread, Beads, Adhesive. Leather consumption is approximately 0.308 sq. ft. The making procedure as follows: At first we visualize and prepare a design of a bangle. Then we prepared the master pattern. According to our design, mark the position of attaching them. Then cut the base pattern within flowers for the bangle. Split and skive if the thickness is more. Place the base leather to cover the wooden frame. Put adhesives to attach the base leather. Add beads with thread to make flowers. Add the flowers with the help of adhesives. Finally, assemble and finishing have been done to ensure the quality. The costing of final bracelet-bangle ca. $23 \mathrm{BD}$ taka and market same item price about 150 350 taka.

\section{RESULTS AND DISCUSSION}

\section{A. Data collection}

A survey questionnaire was made to know the level of satisfaction. The survey have been done on 50 female adult persons. Different types of jewelry have been shown to them, so that they can compare between leather jewelry and metal jewelry.

The questionnaire involves 5 (five) different sector, they are Wearing Comfort, Fashion Fact, Quality, Costing \& Interest in buying and recommendations. Each of the sectors contains 3 different questions to know about the level of satisfaction.

The items are rated on a scale of 1 to 5 , where 1 being "strongly disagree", 2 being "disagree", 3 being "average/undecided", 4 being "agree" and 5 being "strongly agree".

Survey questionnaires are given below:

A. Wearing comfort:

1. I had no trouble wearing these jewelries.

\begin{tabular}{|c|c|c|c|}
\hline 1 & 2 & 3 & 4 \\
\hline
\end{tabular}

\begin{tabular}{|c|c|c|c|c|}
\hline 1 & 2 & 3 & 4 & 5 \\
\hline
\end{tabular}

3. It is more comfortable than any other metal jewelry. \begin{tabular}{|c|c|c|c|c|}
\hline 1 & 2 & 3 & 4 & 5 \\
\hline
\end{tabular}

B. Fashion fact:

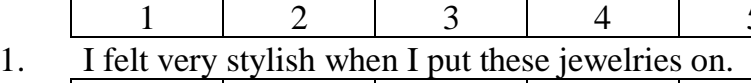

2. These jewelries are helping to increase the fashion appeal of my appearance.

3. These jewelries are totally harmonious with trend.

\begin{tabular}{|c|c|c|c|c|}
\hline 1 & 2 & 3 & 4 & 5 \\
\hline
\end{tabular}

C. Quality:

1. The quality of these jewelries fulfilled my expectation level.

2. I think the quality worth the price.

3. I think the quality is good for both casual and party use.

\begin{tabular}{|l|l|l|l|l|}
\hline 1 & 2 & 3 & 4 & 5 \\
\hline
\end{tabular}




\section{Costing:}

1. I think the price of the jewelry is not overabundant.

2. These jewelries are more cost effective than similar metal jewelries.

3. I would happily buy this type of leather jewelry in such low price.

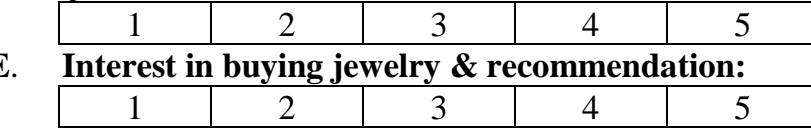

1. I am planning to buy this type of jewelry for my family and friends.

2. I would recommend these jewelries to others.

3. I am more likely to buy other styles of leather jewelries.

\begin{tabular}{|l|l|l|l|l|}
\hline 1 & 2 & 3 & 4 & 5 \\
\hline
\end{tabular}

Any advice to improve the design/quality of these jewelries,

\section{B. Survey analysis}

After taking the survey, the total score, mean value, standard deviation, variance, coefficient of variance, median of each sections have been calculated to determine the level of satisfaction. The total survey sample is 50 for every section as the total number of participant is 50 .

Level of satisfaction calculated by the following formula:

( sample of strongly agree $* 5)+($ sample of agree $* 4)+($ sample of undecided $* 3)+$

$$
\frac{\text { (sample of disagree } * 2)+(\text { sample of strongly disagree } * 1)}{\text { Number of sample }(\mathrm{N}) * 5} * 100
$$

The graph of Fig.7 shows the level of satisfaction of the participants for different sections. The no wearing trouble is $80.4 \%$ whereas regular use and more comfort satisfactory level is $65.2 \%$ and 69.6 respectively. It's can be conclude that regular use and more comfort level of satisfaction is critical and need to be product development. The mean, median, standard deviation, variance and coefficient of variance are $3.59,3.48,0.40,0.15,0.10$ respectively for wearing comfort.

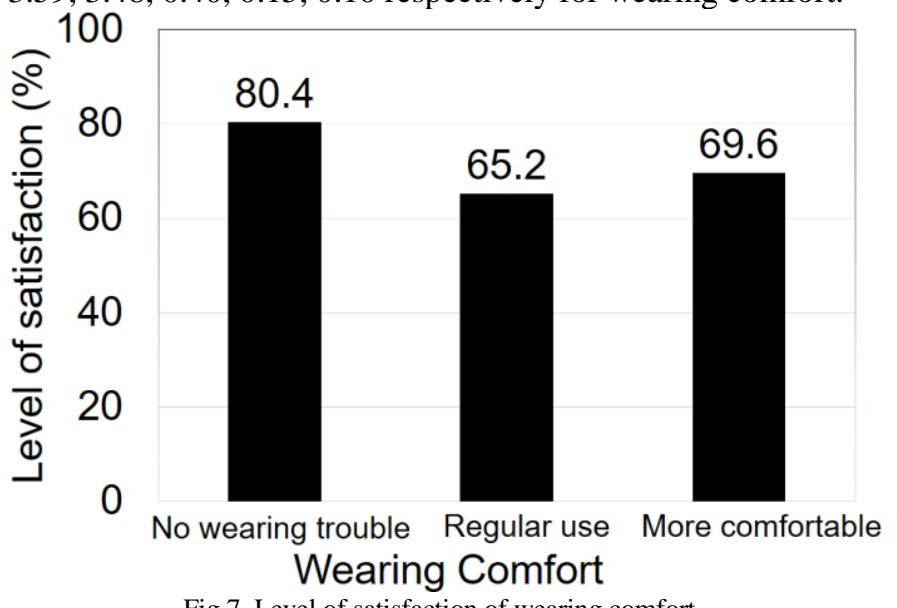

Fig.7. Level of satisfaction of wearing comfort
Fig.8 shows the satisfactory level of fashion fact of jewelry. The graph shows the acceptance level of stylish, fashion appeal and harmonious of the leather jewelry. The mean, median, standard deviation, variance and coefficient of variance are $4,4.06,0.41,0.17,0.10$ respectively for fashion fact.

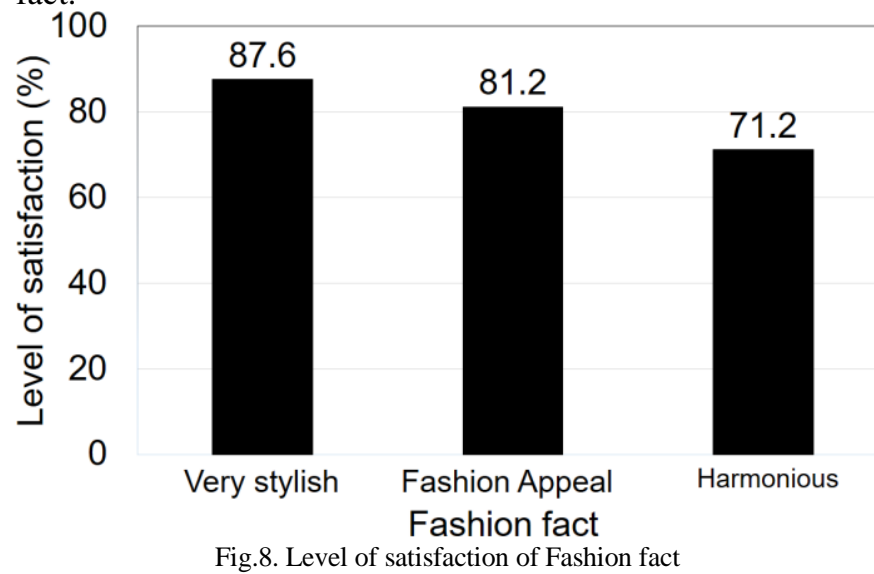

Fig.9 shows the satisfactory level of quality fact of jewelry. The graph shows two of acceptance expectation level of quality, and quality worth of the leather jewelry. However, the quality is not satisfactory level for both casual and party use and needs for further improvement.

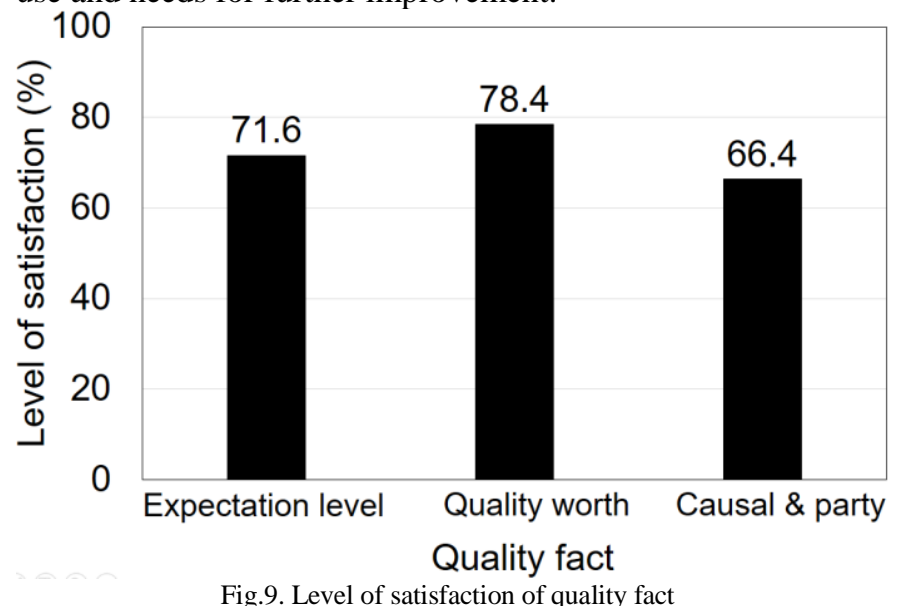

The mean, median, standard deviation, variance and coefficient of variance are 3.60, 3.58, 0.30, 0.090 and 0.083 respectively for the quality fact.

Fig.10 shows the satisfactory level of costing fact of jewelry. The graph shows price overabundant, cost effective and happily, to buy of acceptance level of product cost. The mean, median, standard deviation, variance and coefficient of variance are 4.08, 3.98, 0.26, 0.066 and 0.062 respectively for the costing fact. 


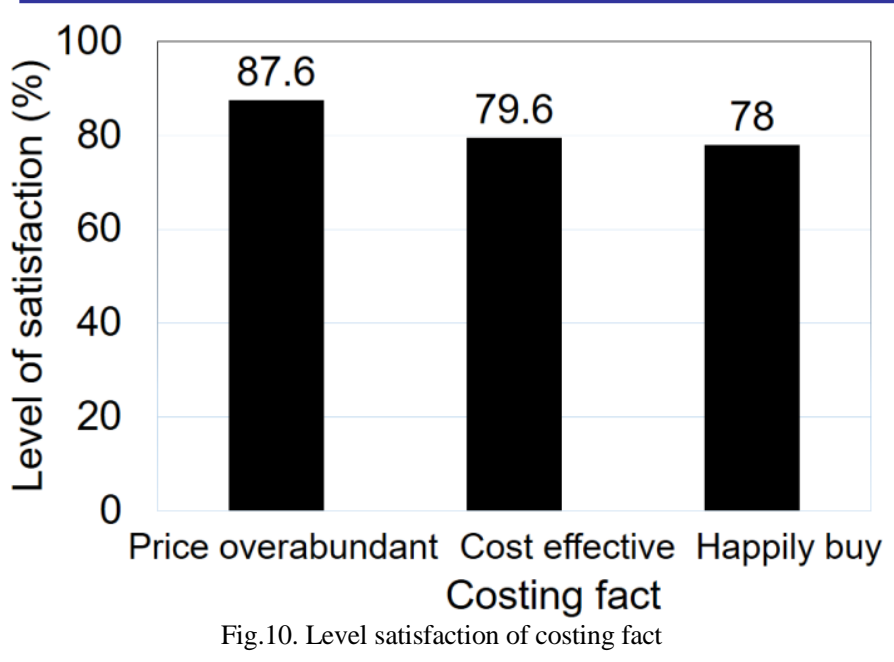

The graph of Fig.11 shows the level of satisfaction of the participants for different sections of interest in buying jewelry $\&$ recommendations to other. I am planning to buy this type of jewelry for me, my family and friends are $71.6 \%$, recommend these jewelries to others is $78.4 \%$ and more likely to buy other styles $79.2 \%$ of leather jewelries level of satisfaction. The mean, median, standard deviation, variance and coefficient of variance are $3.82,3.92,0.20,0.04,0.05$ respectively for interest in buying fact.

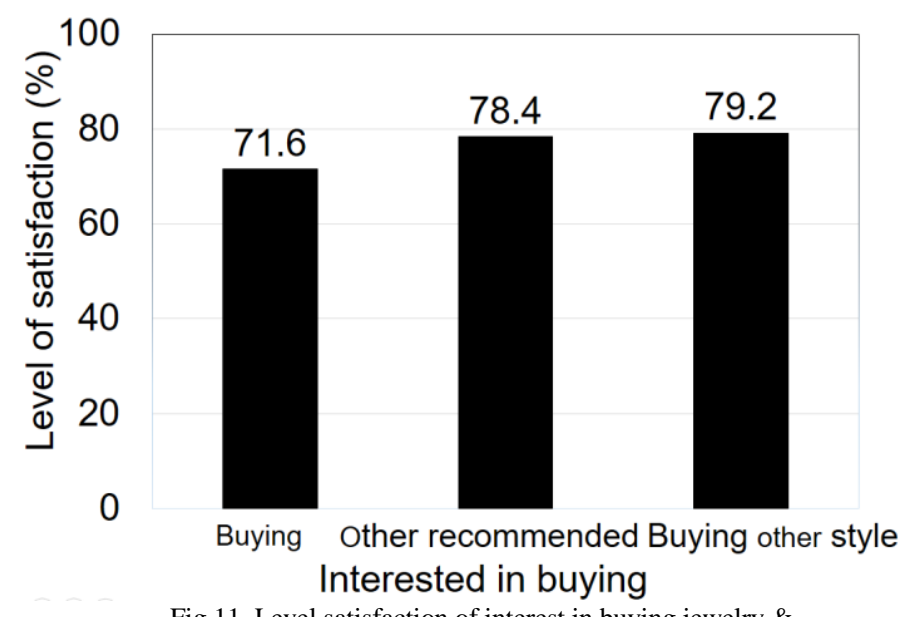

Fig.11. Level satisfaction of interest in buying jewelry \& recommendation

\section{CONCLUSIONS}

The products made out of leather and themselves to an enormous variety of both useful \& essential items, which are a need and asset in modern living. An extensive range of colors $\&$ designs widen the selection range which encourage the prospective consumers to put this product to use in a multitude of ways be it fashionable or functional.

Designing is an important process in the manufacture of ladies jewelries. In the principle of designing, a good design should be easy for fabrication \& saleable. The design should be simple when it is covered into production as much as possible, because production \& productivity are the key factors for successful commercial venture. Assembling of too many components for multipurpose functions must be avoided as much as possible. It affects the important aspects of designing namely, size, shape, structure attraction \& value appearance. In good designing, techniques \& technical skills are very important. A good design should not impart the functions of the products for which they are manufactured.

It is indeed true that we are accustomed and habituated to use small leather goods not only in our life but also in our professional life largely. For instance, we use wallet, passport cases and coin boxes to maintain the daily money handling personally. Notwithstanding, using of leather goods is also a matter of status and prestige and gratifying. It is an irony of fate that making process of small leather goods difficult not only to maintain the quality but also to produce a better shape.

It is imperative that, new entrepreneurship will make a base for exporting the small leather goods after consuming local demands, should consider the customers capability to buy the products. Foreign currency can be gained in a significant way which may develop the country economy as raw material and labor are two most important factor but available in our country.

It can be conclude that, easily increase the level of satisfaction by taking idea and suggestions from the user. It will help us to increase the acceptance of the jewelry and reduce the wastage.

\section{ACKNOWLEDGMENT}

The present research was supported by the Institute of Leather Engineering and Technology, Dhaka University. The authors would like to thank Prof. Dr. Sayed Md. Shamsuddin, Director, ILET, DU for providing insight and expertise that greatly assisted the research. The authors would like to gratefully acknowledge and thanks to Pragati Footwear Ltd, 55/1 Hazaribagh, Dhaka-1209 for collecting the leather wastages.

\section{REFERENCES}

[1] Sandin Gastav, Greg M.Peters, Environmental impact of textile reuse and recycling-A review, Journal of Cleaner Production: 2018, Vol. 184.pp.353-363.

[2] L. Lakshmanan, S. Chinngaihlian, Compititiveness of India's Manufacturing Sector: An Assessment of related Issues. Reserve Bank of India Occasional Papers: 207, Vol. 28, pp. 34-77

[3] G.C. Mosely, "Leather Goods Manufacture”, Reprinted 1947, Sir Isaac Pitman \& Sons Ltd.: London, 1939 , pp.6-7.

[4] B. Nelson, "Manual of Cost Accounting in The Footwear Industry", $1^{\text {st }}$ ed, Published Jointly By The Incorporated Federated Associations of Boot And Shoe Manufacturers of Great Britain and Ireland and The Society of Incorporated Accounts: 1957, pp. 30-31.

[5] J. Buljan, I. Kral, The framework for sustainable leather manufacture, United Nations Industrial Development Organization: 2015, vol. 12, pp.145-147. 